\title{
ALTERAÇÕES MICROCLIMÁTICAS CAUSADAS PELO USO DE TELA PLÁSTICA
}

\section{JOSÉ E. M. PEZZOPANE ${ }^{1}$, PAULO C. DE OLIVEIRA ${ }^{1}$, EDVALDO F. DOS REIS ${ }^{1}$, JULIÃO S. DE S. LIMA ${ }^{1}$}

\begin{abstract}
RESUMO: Com o objetivo de caracterizar as alterações microclimáticas provocadas pelo uso de tela plástica na agricultura, foi desenvolvido um experimento com alface, em área de cultivo agrícola, em Alegre - ES (latitude $20^{\circ} 45^{\prime} \mathrm{S}$, longitude $41^{\circ} 28^{\prime} \mathrm{W}$ e altitude $150 \mathrm{~m}$ ), no período de setembro a dezembro de 1996. Foram utilizados sombreamentos de 0; 30; 50, e 70\%, segundo especificação comercial. Os resultados mostraram que a tela com especificação comercial de $50 \%$ de sombreamento provocou uma atenuação média de $41 \%$ na radiação solar global, ocorrendo, no entanto, uma flutuação significativa ao longo do dia em função do movimento aparente do sol. A cobertura com a tela plástica não provocou alterações significativas da temperatura e umidade relativa do ar. Em relação à temperatura do solo, foi possível verificar uma atenuação com o aumento do sombreamento.
\end{abstract}

PALAVRAS-CHAVE: microclima, tela plástica, sombreamento.

\section{MICROCLIMATOLOGICAL ALTERATIONS CAUSED BY PLASTIC SCREEN USES}

SUMMARY: The objective of this study was to determine the micrometeorological alterations caused by plastic screen uses in agriculture. The experiment with lettuce was carried out in Alegre $\left(20^{\circ} 45^{\prime} \mathrm{S}\right.$, $41^{\circ} 28^{\prime} \mathrm{W}-150 \mathrm{~m}$ ), Espírito Santo State, Brazil, during September to December, 1996. Measurements were done under plastic screen with $0 ; 30 ; 50$, and $70 \%$ of solar radiation reduction (attenuation) according to commercial specification. Results showed that attenuation was less than commercial specification and there was a diurnal fluctuation as a function of solar zenital angle. A reduction in soil temperature under shading was also observed.

KEYWORDS: microclimate, plastic screen, shading.

\section{INTRODUÇÃO}

Em algumas regiões do Brasil, tem crescido o uso de tela plástica na agricultura com o objetivo de atenuar a densidade de fluxo de radiação solar, possibilitando o cultivo, principalmente de olerícolas, em épocas com alta disponibilidade energética. A caracterização dessa atenuação da radiação solar é importante, pois afeta os outros componentes do balanço de energia, como os fluxos de calor sensível e latente, além do processo fotossintético.

Diversos trabalhos têm mostrado que o uso de sombreamento artificial através de ripados ou telas plásticas causa uma modificação no balanço de energia radiante, propiciando características mais adequadas às espécies de baixo ponto de saturação luminosa (SEDYAMA \& PRATES, 1986). SALVATIERRA et al. (1991), BURIOL et al. (1994) e SOUZA et al. (1995) mostram que o uso de tela de polietileno provoca uma redução da radiação fotossinteticamente ativa, bem como na porção do infravermelho próximo, além de alterar a temperatura do ar e do solo.

\footnotetext{
${ }^{1}$ Professor Adjunto, Departamento de Engenharia Rural, Universidade Federal do Espírito Santo, Caixa Postal 16, Alegre - ES, e-mail: jemp@npd.ufes.br

Recebido pelo Conselho Editorial em: 12-3-2001

Aprovado pelo Conselho Editorial em: 6-11-2003

Eng. Agríc., Jaboticabal, v.24, n.1, p.9-15, jan./abr. 2004
} 
O excesso de radiação solar pode causar um prejuízo direto à planta, afetando a assimilação de $\mathrm{CO}_{2}$ através da fotossíntese, devido a um processo conhecido como fotoinibição, sendo bastante comum em plantas que possuem as chamadas folhas de sombra, com características estruturais e concentração de pigmentos adaptados a baixa intensidade de luz (PEARCY et al., 1996). Também, o excesso de energia pode afetar o crescimento e o desenvolvimento das plantas de maneira indireta por meio, por exemplo, de uma demanda excessiva de água, causando estresse hídrico mesmo havendo água disponível no solo (LARCHER, 1995). MATTEI et al. (1973) verificaram que a redução da quantidade de energia incidente de 100 a $200 \mathrm{cal} \mathrm{cm}^{-2} \mathrm{dia}^{-1}$ foi benéfica para o crescimento de duas cultivares de alface, além de reduzir a evapotranspiração, o que promoveu uma redução significativa no uso de água na irrigação. SANCHEZ et al. (1989) observaram um ponto de compensação lumínico ao redor de $800 \mu \mathrm{mol} \mathrm{m} \mathrm{m}^{-2}$ para cultivares de alface. Esse valor pode ser facilmente ultrapassado em muitas regiões, dependendo da latitude e época do ano, inclusive em horários em que se esperam altos valores de fotossíntese, ou seja, pela manhã. Trabalhos realizados com essências florestais típicas de sub-bosque evidenciaram sérios danos causados pela fotoinibição, com drástica redução de crescimento ou até mesmo morte de plântulas (KONIGER et al., 1995; CRITCHLEY, 1998).

O presente trabalho teve como objetivo estudar modificações microclimáticas provocadas pelo uso de tela plástica em cultivos agrícolas na Região do Vale do Rio Itapemirim - ES.

\section{MATERIAL E MÉTODOS}

O experimento foi conduzido na área experimental do Centro de Ciências Agrárias da UFES, em Alegre - ES (latitude 2045'S, longitude 41 $28^{\prime} \mathrm{W}$ e altitude $150 \mathrm{~m}$ ). O clima da região, segundo classificação de Köeppen, é do tipo "Aw", com estação seca no inverno; temperatura anual média de $23,1{ }^{\circ} \mathrm{C}$ e precipitação anual em torno de $1.200 \mathrm{~mm}$.

O estudo microclimático foi realizado em canteiros cultivados com alface em sistema tradicional, com espaçamento de $20 \times 20 \mathrm{~cm}$. Os dados foram obtidos entre setembro e dezembro de 1996, em área plana a céu aberto e sob telas plásticas com sombreamento de 30; 50 e 70\%, segundo a especificação comercial, instaladas horizontalmente a $1 \mathrm{~m}$ de altura. A área de cada tratamento era de $60 \mathrm{~m}^{2}(6 \mathrm{x}$ 10 m). O solo recebeu irrigação diariamente, sendo mantido sempre próximo à capacidade de campo.

A radiação solar foi monitorada a céu aberto e sob a tela plástica com sombreamento de $50 \%$, com sensores instalados a $25 \mathrm{~cm}$ de altura. A radiação líquida foi medida com radiômetro modelo Q-7, marca REBS; a radiação solar global com piranômetro modelo LI200X, e a radiação fotossinteticamente ativa com radiômetro modelo LI190SB, ambos da marca LI-COR. A análise do comportamento da radiação solar foi feita com base nos dados registrados entre 8 e 16 horas, por não haver qualquer influência das estruturas montadas para a realização do estudo, devido ao ângulo zenital do Sol. A radiação solar não foi avaliada nos sombreamentos de 30 e $70 \%$ devido ao reduzido número de sensores disponíveis.

A temperatura do ar e do solo, além da umidade relativa do ar, foram monitoradas a céu aberto e sob todos os tratamentos sombreados. A temperatura e a umidade relativa do ar foram medidas em microabrigos instalados a $25 \mathrm{~cm}$ de altura, e a temperatura do solo foi medida a $5 \mathrm{~cm}$ de profundidade, na parte central dos canteiros. Na medição da temperatura, foram utilizados sensores modelo 107, marca Campbell e, na medição de umidade relativa sensores modelo HMP35, marca Vaisala. Os dados foram coletados por meio de sistema automático de aquisição de dados, modelo CR10, marca Campbell, programado para leitura a cada minuto e cálculo de médias a cada 15 minutos, com armazenamento de valores extremos. 
Para a análise dos dados, foram ajustados modelos de regressão escolhidos com base na significância dos coeficientes de regressão, utilizando o teste " $\mathrm{t}$ ", adotando-se o nível de 5\% de probabilidade.

\section{RESULTADOS E DISCUSSÃO}

O conhecimento da transmissividade real do material é de fundamental importância para uma melhor aplicação prática de resultados de experimentos que indiquem o sombreamento mais adequado para o crescimento e o desenvolvimento de uma espécie vegetal qualquer. A atenuação média da radiação solar global $(\mathrm{Rg})$, entre 8 e 16 horas, durante todo o período de experimentação, foi 41,1\%, sendo, portanto, menor em relação à especificação comercial da tela utilizada (50\%). A mesma tendência foi observada no caso da radiação solar fotossinteticamente ativa (PAR) e do saldo de radiação $(\mathrm{Rn})$, conforme Tabela 1.

TABELA 1. Valores médios de radiação solar global (Rg), radiação fotossinteticamente ativa (PAR) e saldo de radiação (Rn) a céu aberto e sob tela plástica com sombreamento de $50 \%$, entre 8 e 16 horas, durante 61 dias, no período de setembro a dezembro de 1996, em Alegre - ES.

\begin{tabular}{ccc}
\hline Radiação & Céu Aberto & Tela Plástica \\
\hline $\operatorname{Rg}\left(\mathrm{W} \mathrm{m}^{-2}\right)$ & 472 & 278 \\
$\operatorname{PAR}\left(\mu \mathrm{mol} \mathrm{m}^{-2} \mathrm{~s}^{-1}\right)$ & 978 & 548 \\
$\operatorname{Rn}\left(\mathrm{W} \mathrm{m}^{-2}\right)$ & 327 & 200 \\
\hline
\end{tabular}

O estudo da radiação solar na superfície é importante, uma vez que o balanço de radiação determina a energia disponível para processos como evaporação, aquecimento ou resfriamento do ar e do solo e para a fotossíntese. Assim, a redução drástica do saldo de radiação (Rn) observada na Figura 1 deve resultar em modificações microclimáticas significativas, alterando $\mathrm{o}$ crescimento e desenvolvimento das plantas sob a tela plástica. No dia exemplificado, próximo ao meio-dia, a redução de $\mathrm{Rn}$ foi ao redor de $38 \%$.

Os resultados ainda mostram uma flutuação do valor porcentual do sombreamento ao longo do dia, principalmente em condição de ausência de nuvens. No dia apresentado na Figura 2, no horário de maior incidência de radiação, ao redor do meio-dia, o sombreamento foi próximo a $35 \%$, enquanto às 8 e $16 \mathrm{~h}$ os valores foram superiores a 45\%, evidenciando uma influência do movimento aparente do Sol. No dia apresentado na figura, ao meio-dia, o ângulo zenital é $30^{\circ}$, o que facilitou a penetração dos raios solares através da tela plástica, ao contrário das $8 \mathrm{~h}$, quando o ângulo zenital é $75^{\circ}$. Assim, fica claro que fatores como latitude local, época do ano e horário do dia controlam a atenuação da radiação solar pela tela plástica. Isso é importante, pois a recomendação sobre densidade ideal de tela para o cultivo de uma determinada espécie pode ser diferente de uma região para outra. Vale destacar que, no presente trabalho, a tela plástica foi instalada horizontalmente, e que, no caso de construções no formato de túneis, a interação entre os raios solares e a tela pode resultar em valores diferentes de transmissividade.

Diversas pesquisas realizadas com espécies florestais procuram simular a situação de baixa disponibilidade energética no sub-bosque da floresta. Entretanto, a absorção da radiação solar pelo dossel da floresta é seletiva, sendo alta na faixa espectral do visível e baixa no infravermelho próximo. Estudando a relação PAR/Rg em floresta tropical, LEE (1987) encontrou valores ao redor de 0,54 sobre a floresta e 0,17 no nível do solo. Assim, é importante a determinação da relação entre PAR e Rg sob a tela plástica, uma vez que essa envolve a energia disponível para o processo fotossintético. Ajustando um modelo linear simples, passando pela origem das coordenadas, visando a estimar a PAR 
$\left(\mu \mathrm{mol} \mathrm{m} \mathrm{m}^{-2} \mathrm{~s}^{-1}\right)$ em função da radiação solar global, encontraram-se coeficientes angulares similares para a condição exterior $(2,06)$ e sob a tela $(1,97)$, mostrando não haver uma atenuação seletiva quanto a PAR em relação a $\mathrm{Rg}$ (Figura 3). O teste de identidade de modelos mostrou não existir diferença estatística entre os dois modelos.

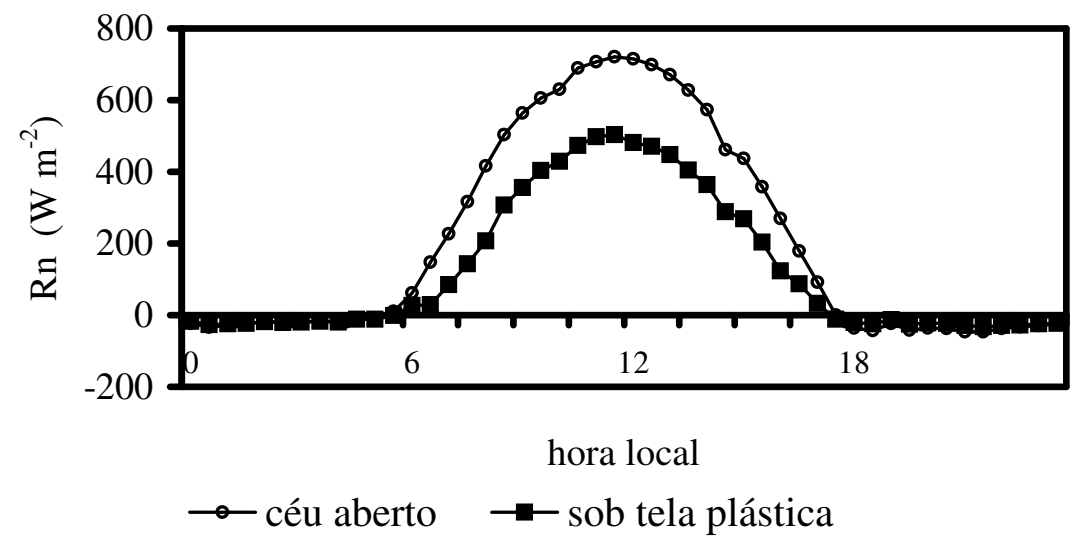

FIGURA 1. Saldo de radiação $(\mathrm{Rn})$, em condição de céu aberto e sob tela plástica, no dia 8 de novembro de 1996.

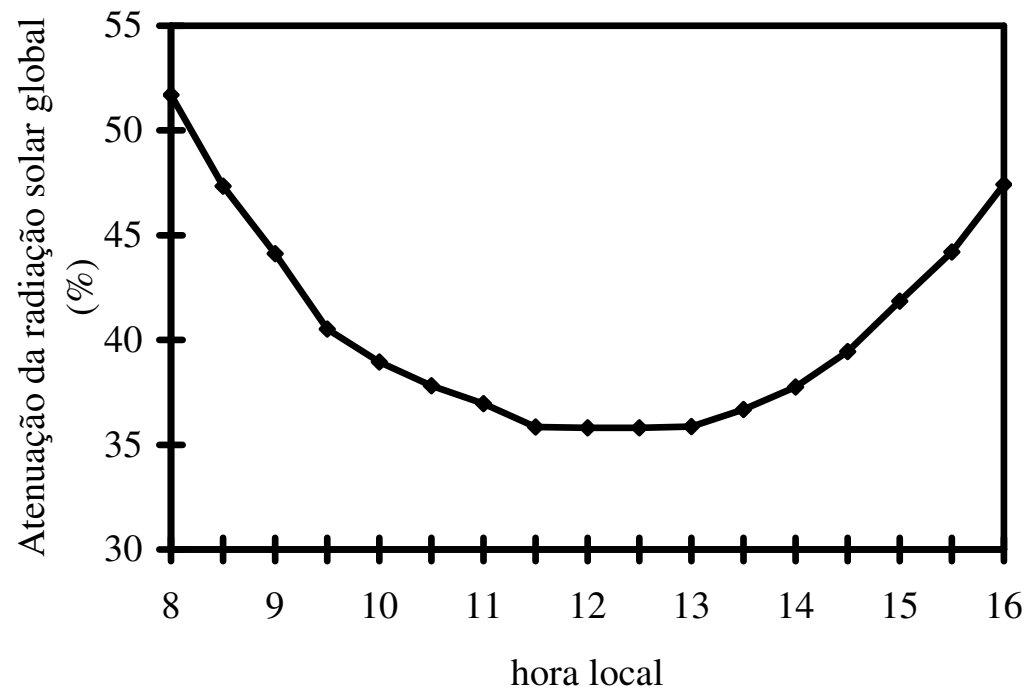

FIGURA 2. Atenuação da radiação solar global (\%), observada sob tela plástica com sombreamento comercial igual a 50\%, no dia 22 de setembro de 1996.

Na Tabela 2, apresentam-se as equações de regressão estabelecendo a relação entre temperatura do ar e do solo com o sombreamento aplicado. O sombreamento não provocou alteração significativa da temperatura média, máxima e mínima do ar, mesmo com a atenuação da disponibilidade energética. Isso pode ter ocorrido devido à reduzida área sombreada, não existindo bordadura suficiente para provocar, principalmente, uma redução significativa da temperatura diurna do ar. Provavelmente, um estudo da temperatura foliar mostraria maiores diferenças. A umidade relativa sob a tela plástica foi a mesma observada na condição de céu aberto, apresentando um valor médio de $83 \%$. 


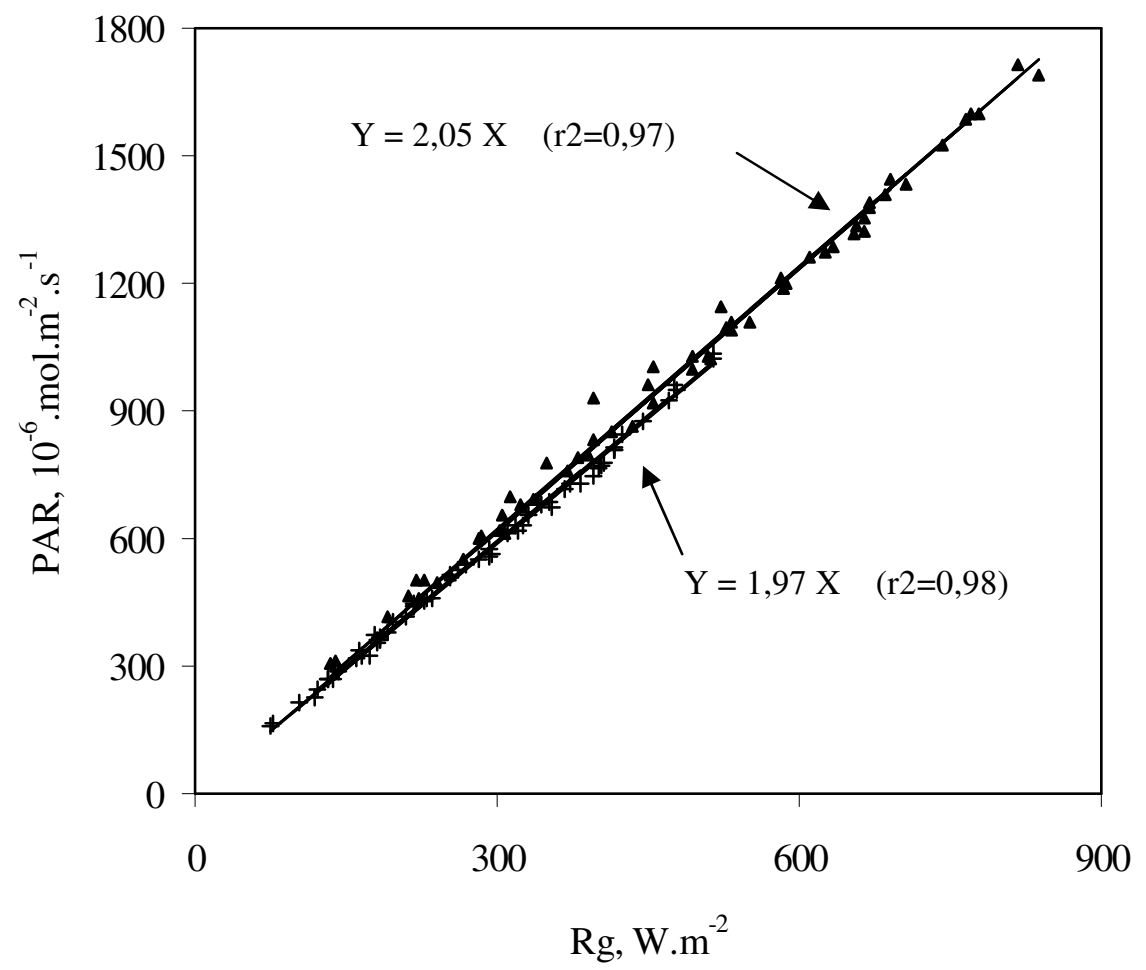

FIGURA 3. Estimativa da radiação solar fotossinteticamente ativa (PAR) em função da radiação solar global $(\mathrm{Rg})$, entre 8 e 16 horas, utilizando dados medidos no período de setembro a dezembro de 1996.

TABELA 2. Equações para estimar as temperaturas média, máxima e mínima diária do ar e do solo em função do sombreamento provocado por tela plástica, em que " $\mathrm{X}$ " corresponde ao sombreamento $(\%)$ e "Y" à temperatura $\left({ }^{\circ} \mathrm{C}\right)$.

\begin{tabular}{cccc}
\hline Temperatura & & Equação & \\
\hline & média & $\mathrm{Y}=22,84+0,002 \mathrm{X}$ & n.s. \\
Ar $(25 \mathrm{~cm}$ de altura $)$ & máxima & $\mathrm{Y}=29,35-0,002 \mathrm{X}$ & n.s. \\
& mínima & $\mathrm{Y}=19,01+0,003 \mathrm{X}$ & n.s. \\
\hline \multirow{3}{*}{ Solo $(5 \mathrm{~cm}$ de profundidade $)$} & média & $\mathrm{Y}=25,80-0,019 \mathrm{X}$ & n.s. \\
& máxima & $\mathrm{Y}=31,25-0,071 \mathrm{X}$ & $*$ \\
& mínima & $\mathrm{Y}=22,78+0,005 \mathrm{X}$ & n.s. \\
\hline
\end{tabular}

* significativo a 5\% de probabilidade; n.s. não significativo

Com relação à temperatura do solo, o sombreamento causou uma redução significativa na temperatura máxima, havendo também uma tendência de aumento da temperatura mínima, provavelmente devido à proteção auferida pela tela plástica no período noturno. As diferenças foram marcantes em dias com céu claro, ou seja, alta disponibilidade energética, principalmente nos horários mais quentes do dia (Figura 4). No dia representado na Figura 4, a temperatura máxima foi 34,6; 30,6; 29,9 e $27,7{ }^{\circ} \mathrm{C}$, para os tratamentos com $0 ; 30 ; 50$ e $70 \%$ de sombreamento, respectivamente.

Provavelmente, a diferença de temperatura do solo entre os tratamentos seria maior com baixos valores de teor de água no solo. PEZZOPANE et al. (1996), trabalhando na mesma área e época do ano, encontraram com freqüência temperatura máxima acima de $40{ }^{\circ} \mathrm{C} \mathrm{em} \mathrm{solos} \mathrm{secos.} \mathrm{Os} \mathrm{maiores}$ valores de temperatura máxima e os menores de temperatura mínima resultaram em maior amplitude térmica do solo no tratamento a céu aberto. Na Figura 5, verifica-se haver uma estabilização da 
amplitude térmica a partir de $60 \%$ de sombreamento. Essa modificação microclimática provocada pela tela plástica, provavelmente, reduz também a perda de água por evapotranspiração.

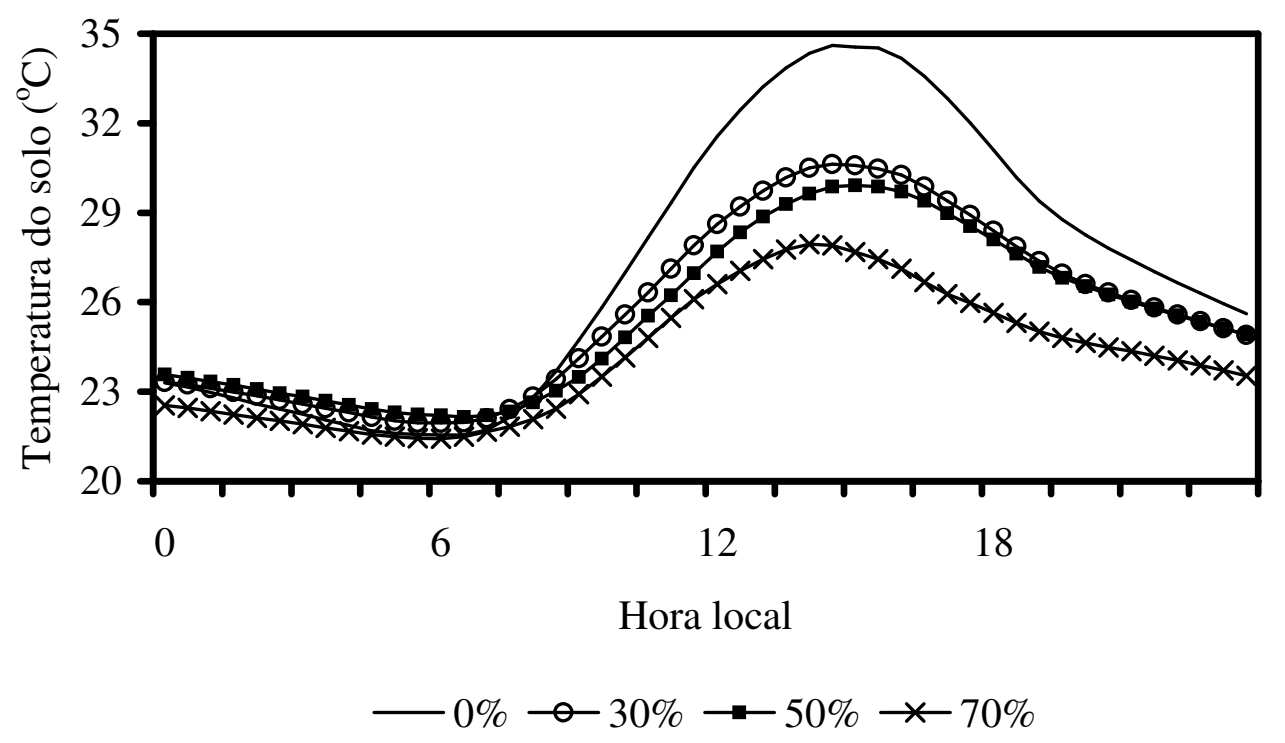

FIGURA 4. Temperatura do solo (5 $\mathrm{cm}$ de profundidade) sob sombreamento de $0 ; 30 ; 50$ e $70 \%$, no dia 8 de novembro de 1996. UFES, Alegre - ES.

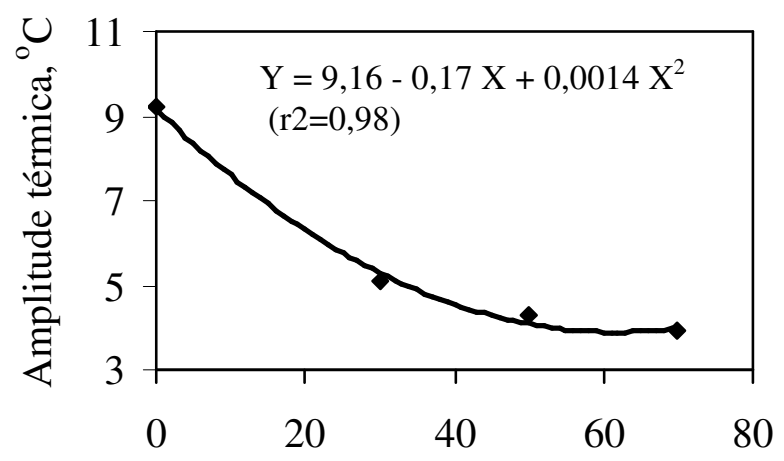

Sombreamento, \%

FIGURA 5. Amplitude térmica diária do solo em função do porcentual de sombreamento (valor comercial) provocado por tela plástica, no período de setembro a dezembro de 1996.

A região do Vale do Rio Itapemirim, no Estado do Espírito Santo, destaca-se por possuir um período primavera-verão com alta densidade de fluxo de radiação solar, o que, associado a altas temperaturas, inviabiliza o cultivo de olerícolas e a produção de mudas de algumas espécies florestais e frutíferas nessa época do ano. Assim, diante dos resultados obtidos no presente estudo, o uso de telas sombreadoras pode provocar alterações microambientais, viabilizando o cultivo ou produção de algumas espécies de interesse econômico.

\section{CONCLUSÕES}

Os resultados permitem concluir que a atenuação da radiação solar provocada pela tela plástica flutua ao longo do dia em função do ângulo zenital do Sol, não sendo seletiva, pois a relação entre Rg e PAR é a mesma a céu aberto e sob o ambiente protegido. A variável microclimática mais afetada foi a 
temperatura do solo, que apresentou menores valores nos horários mais quentes do dia na área cultivada sob tela, com conseqüente redução da amplitude térmica.

\section{REFERÊNCIAS BIBLIOGRÁFICAS}

BURIOL, G.A.; STRECK, N.A.; GIMENES, E.S.; SCHINEIDER, F.M. Alterações

micrometeorológicas causadas por túneis baixos de tela plástica preta cultivados com alface. Ciência Rural, Santa Maria, v.24, p.1-6, 1994.

CRITCHLEY, C. Photoinhibition. In: RAGHAVENDRA, A.S. (Ed.) Photosynthesis: a comprehensive treatise. Cambridge: Cambridge Press, 1998. p.264-72.

KONIGER, M.; HARRIS, G.C.; VIRGO, A.; WINTER, K. Xanthophyll-cycle pigments and photosynthetic capacity in tropical forest species: a comparative field study canopy, gap and understory plants. Oecologia, Berlin, v.104, n.1, p.280-90, 1995.

LARCHER, W. Physiological plant ecology. New York: Springer, 1995. 506 p.

LEE, D.W. The spectral distribution of radiation in two neotropical rainforests. Biotropica, London, v.19, n.2, p.161-6, 1987.

MATTEI, F.; SEBASTIANI, L.A.; GIBBSON, D. The effect of radiant energy on growth of Lactuca sativa L. Journal of Horticultural Science, London, v.48, n.1, p.311-13, 1973.

PEARCY, R.W.; KRALL, J.P.; SASSENRATH-COLO, G.F. Photosynthesis in fluctuating light environment. In: BAKER, N.R. (Ed.) Photosynthesis and the environment. New York: Kluwer, 1996. p.321-46.

PEZZOPANE, J.E.M.; CUNHA, G.M.; ARNSHOLZ, E.; COSTALONGA, M. Temperatura do solo em função da cobertura morta por palha de café. Revista Brasileira de Agrometeorologia, Santa Maria, v.4, n.2, p.7-10, 1996.

SALVATIERRA, E.; BURIOL, G.A.; ANDRIOLO, J.L. Modificação ambiental causada por tela de polietileno. I - efeito sobre a disponibilidade de energia solar, temperatura do solo e do ar. In: CONGRESSO BRASILEIRO DE AGROMETEOROLOGIA, 7., 1991, Viçosa - MG. Anais... Viçosa MG: Sociedade Brasileira de Agrometeorologia, 1991. p.293.

SANCHEZ, C.A.; ALLEN, R.J.; SCHAFLER, B. Growth and yield of crisphead lettuce under various shade conditions. Journal of the American Society for Horticultural Science, Alexandria, v.114, p.88490, 1989.

SEDYAMA, G.C.; PRATES, J.E. O microclima: possibilidade de modificações. Informe Agropecuário, Belo Horizonte, v.12, p.36-42, 1986.

SOUZA, D.K.S.; LOPES, M.J.A.; NASCIMENTO FILHO, M.F. Efeito da tela plástica na temperatura do solo e radiação solar na cultura do pimentão. In: CONGRESSO BRASILEIRO DE AGROMETEOROLOGIA, 9., 1995, Campina Grande. Anais... Campina Grande: Sociedade Brasileira de Agrometeorologia, 1995. p.339-41. 